\title{
Feasibility of Concomitant Chemoradiotherapy in Daily Practice for Patients with NSCLC Stage III
}

\author{
FEMKE S. VAN DER MEER ${ }^{1}$, FRANZ M.N.H SCHRAMEL ${ }^{1}$, \\ MARCO VAN VULPEN ${ }^{2}$ and SHERIF Y. EL SHAROUNI ${ }^{2}$ \\ ${ }^{1}$ Department of Pulmonology, St. Antonius Hospital, Nieuwegein, the Netherlands; \\ ${ }^{2}$ Department of Radiotherapy, University Medical Centre Utrecht, Utrecht, the Netherlands
}

\begin{abstract}
Background: In patients with non-small cell lung cancer (NSCLC), approximately 25\% have locally advanced disease. For patients with irresectable (N2-3 or T4) or inoperable disease, treatment consists of chemoradiotherapy. Concomitant chemoradiotherapy improves survival compared to sequential chemoradiotherapy in these patients. Patients and Methods: Treatment plans and completion of treatment was evaluated for all patients treated at the St. Antonius Hospital from 2008-2011 for NSCLC stage IIIA/B not eligible for surgery. Results: Between 2008 and 2011, 180 patients with NSCLC stage III were treated at our hospital. A total of 152 patients were not eligible for surgery; in 78 (51\%) patients, primary treatment was chemoradiotherapy; 31 (20\%) were planned for concomitant treatment. The most frequent reasons for refraining from concomitant chemoradiotherapy were limitations of radiotherapy constraints and condition of the patients (87\%). Conclusion: Although concomitant chemoradiotherapy is the standard-of-care in patients with stage IIIA/B NSCLC ineligible for surgery, the majority (80\%) of the patients were treated otherwise.
\end{abstract}

For patients with non-small cell lung cancer (NSCLC) stage IIIA/B who are ineligible for surgery [irresectable (N2-3 or T4) or inoperable], the standard treatment consists of concomitant chemoradiotherapy (1). Combining chemotherapy with thoracic radiotherapy demonstrated a survival benefit when compared to thoracic radiotherapy alone [absolute benefit of $2 \%$ at 2 years; relative risk of death at 2 years 0.87 ,

This article is freely accessible online.

Correspondence to: Franz M.N.H. Schramel, Department of Pulmonology, St. Antonius Hospital, PO Box 2500, 3430 EM Nieuwegein, the Netherlands. Tel: +31 883201425, Fax: +31 883201449, e-mail: f.schramel@antoniusziekenhuis.nl

Key Words: Non-small cell lung carcinoma, stage III, chemoradiotherapy, therapy.
$95 \%$ confidence interval $(\mathrm{CI})=0.81-0.94$; pooled odds ratio at 2 years $0.70,95 \% \mathrm{CI}=0.5-0.9)(2-4)$.

Concomitant chemoradiotherapy improves survival compared to sequential treatment in patients with locally advanced NSCLC (increase in median survival of 1-3.4 months) $(5,6)$. However this treatment has shown higher toxicity than sequential chemoradiotherapy. A meta-analysis demonstrated a higher risk of acute grade 3-4 esophageal toxicity in concomitant versus sequential chemoradiotherapy (18\% vs. 4\%) (6). No difference was seen in subgroups based on age, sex, histology, tumor stage or performance score. Although concomitant chemoradiotherapy is the standard treatment, it has a higher toxicity and might not be feasible for all patients.

Indications to refrain from chemoradiotherapy and opt for palliative treatment with chemotherapy, radiotherapy, local therapy or best supportive care are: Eastern Cooperative Oncology Group performance score (ECOG PS) greater than 2 , advanced age ( $>80$ years), co-morbidities [American Society of Anesthesiologists classification (ASA) class $>3$ ], contra-indications for chemotherapy or radiotherapy (e.g. renal insufficiency or pulmonary fibrosis), limitations of radiation due to organs at risk (exceeding the radiotherapy constraints, see Table I), other acute treatment indications (such as radiotherapy for hemoptysis or a superior vena cava syndrome) and patient desire.

If a patient can be treated with chemoradiotherapy, the patient is eligible for concomitant treatment when the patient has an ECOG PS 0-1 and limited comorbidity (ASA class 1 and 2).

We intended to examine treatment plans and completion of treatment at our hospital in patients with NSCLC stage III who were not eligible for surgery. We hypothesized based on previously mentioned studies that most patients would be treated with concomitant chemoradiotherapy and complete this treatment.

\section{Patients and Methods}

We performed a retrospective cohort study. A hospital database of all lung cancer patients treated at the St. Antonius Hospital Nieuwegein was explored to review treatment plans and completion 
Table I. Tissue dose-volume constraints for conventional fractionated radiotherapy.

Organ Constraints

Myelum $\quad \mathrm{D}_{\max } 50 \mathrm{~Gy}(\mathrm{EQD} 2, \alpha / \beta=2 \mathrm{~Gy})$

Lungs Lung GTV, V20Gy $<35 \%$, mean lung dose $<20$ Gy

Esophagus Mean dose $\leq 45$ Gy

Hart Mean dose $\leq 45 \mathrm{~Gy}$

Plexus
No solid constraint, for registration

No solid constraint, for registration

No solid constraint, for registration

$\mathrm{D}_{\max }$ : Maximum dose; EQD2: equivalent dose in 2Gy fraction; GTV: gross tumor volume; V20Gy: volume receiving $20 \mathrm{~Gy}$ or more. 
Table II. Primary treatment plan.

\begin{tabular}{lrrr}
\hline & \multicolumn{2}{c}{ Disease stage } & \\
\cline { 2 - 3 } Treatment & IIIA & IIIB & Total N (\%) \\
\hline \multirow{2}{*}{ Chemoradiation, $\mathrm{n}$} & 39 & 39 & $78(51)$ \\
$\quad$ Concomitant & 21 & 10 & $31(20)$ \\
$\quad$ Sequential & 18 & 29 & $47(31)$ \\
Chemotherapy, $\mathrm{n}$ & 7 & 15 & $22(14)$ \\
Radiotherapy, $\mathrm{n}$ & 10 & 6 & $16(11)$ \\
Best supportive care, $\mathrm{n}$ & 16 & 16 & $32(21)$ \\
Other, n & 3 & 1 & $4(3)$ \\
Total & 75 & 77 & 152 \\
\hline
\end{tabular}

switched to sequential treatment at their request, another patient's condition deteriorated and the last patient had a suspicion of a cerebral metastasis or primary tumor. In two patients, treatment was interrupted by toxicity, both developed a pulmonary infection. In one patient, no reason to discontinue treatment was documented.

In 15 out of the 47 patients planned for sequential therapy, treatment was not completed. One patient died before
Table III. Characteristics of patients planned for chemoradiotherapy.

\begin{tabular}{|c|c|c|c|}
\hline & \multicolumn{2}{|c|}{ Chemoradiotherapy type } & \multirow[b]{2}{*}{$p$-Value } \\
\hline & Concomitant & Sequential & \\
\hline Number of patients & 31 & 47 & \\
\hline Mean age, years & 60 & 64 & 0.167 \\
\hline ECOG performance score, $n$ & & & 0.370 \\
\hline $0-1$ & 23 & 33 & \\
\hline$>1$ & 2 & 7 & \\
\hline$>2$ & 0 & 2 & \\
\hline Unknown & 6 & 7 & \\
\hline Co-morbidity/ASA score & & & 0.128 \\
\hline 1 & 15 & 14 & \\
\hline 2 & 12 & 16 & \\
\hline 3 & 3 & 14 & \\
\hline Unknown & 1 & 3 & \\
\hline Mean FEV1, 1 & 0.76 & 0.71 & 0.354 \\
\hline Unknown (n) & 8 & 13 & \\
\hline Stage & & & 0.005 \\
\hline IIIA & 23 & 20 & \\
\hline IIIB & 8 & 27 & \\
\hline $\begin{array}{l}\text { Mean survival from } \\
\text { diagnosis, days }\end{array}$ & 934 & 595 & 0.058 \\
\hline
\end{tabular}

FEV1: Forced expiratory volume; ECOG: Eastern Cooperative Oncology Group; ASA: American Society of Anesthesiologists classification. 
or IIIB disease was significantly different between the groups treated concomitantly or sequentially.

In a meta-analysis of toxicity, mainly esophageal toxicity was higher in those undergoing concomitant treatment compared to those undergoing sequential treatment (6). In our cohort, toxicity or discontinuation of treatment in the concomitantly treated group was not significantly different: in 2 out of the 31 $(6 \%)$ concomitantly treated patients and 4 out of the $47(8 \%)$ sequentially treated patients, toxicity caused discontinuation of therapy. The total discontinuation rate was 11 out of $31(35 \%)$ in concomitantly treated patients and 15 out of the $47(32 \%)$ sequentially treated patients. The current criteria seem appropriate to select patients for concomitant treatment.

Limitations of this study are the small sample size and the retrospective design. For some patients, the reason for the choice of therapy was not found in the electronic patient record. The feasibility to treat with (concomitant) chemoradiotherapy was assessed in a multidisciplinary tumor board. Some patients exceeded the radiotherapy constraints at the intake/planning CT at the Radiotherapy Department. This was scored as discontinuation of treatment and may have negatively influenced our estimation of treatment feasibility.

\section{Conclusion}

Although concurrent chemoradiotherapy is the standard treatment for patients with stage III A/B NSCLC who are not eligible for surgery, only $20 \%$ of patients were treated with concomitant chemoradiotherapy. Reasons for refraining from concomitant treatment were exceeding radiotherapy constraints and poor condition of the patient. This might be related to the significantly higher number of patients with stage IIIB disease in the sequential treatment group. In patients planned for concurrent treatment, no greater toxicity or discontinuation of treatment was seen compared to patients planned for sequential treatment.

\section{References}

1 Ettinger DS, Wood DE, Akerley W, Bazhenova LA, Borghaei H, Camidge DR, Cheney RT, Chirieac LR, D'Amico TA, Demmy TL, Dilling TJ, Dobelbower MC, Govindan R, Grannis FW Jr, Horn L, Jahan TM, Komaki R, Krug LM, Lackner RP, Lanuti M, Lilenbaum R, Lin J, Loo BW Jr., Martins R, Otterson GA,
Patel JD, Pisters KM, Reckamp K, Riely GJ, Rohren E, Schild SE, Shapiro TA, Swanson SJ, Tauer K, Yang SC, Gregory K, Hughes $\mathrm{M}$ and National comprehensive cancer network: NonSmall Cell Lung Cancer, Version 6.2015. J Natl Compr Canc Netw 13: 515-524, 2015.

2 Non-small Cell Lung Cancer Collaborative Group: Chemotherapy in non-small cell lung cancer: a meta-analysis using updated data on individual patients from 52 randomised clinical trials. BMJ 311: 899-909, 1995.

3 Pritchard RS and Anthony SP: Chemotherapy plus radiotherapy compared with radiotherapy alone in the treatment of locally advanced, unresectable, non-small-cell lung cancer. A metaanalysis. Ann Intern Med 125: 723-729, 1996.

4 Marino P, Preatoni A and Cantoni A: Randomized trials of radiotherapy alone versus combined chemotherapy and radiotherapy in stages IIIa and IIIb nonsmall cell lung cancer. A meta-analysis. Cancer 76: 593-601, 1995.

5 Curran WJ Jr., Paulus R, Langer CJ, Komaki R, Lee JS, Hauser S, Movsas B, Wasserman T, Rosenthal SA, Gore E, Machtay M, Sause W and Cox JD: Sequential vs. concurrent chemoradiation for stage III non-small cell lung cancer: randomized phase III trial RTOG 9410. J Natl Cancer Inst 103: 1452-1460, 2011.

6 Aupérin A, Le Péchoux C, Rolland E, Curran WJ, Furuse K, Fournel P, Belderbos J, Clamon G, Ulutin HC, Paulus R, Yamanaka T, Bozonnat MC, Uitterhoeve A, Wang X, Stewart L, Arriagada R, Burdett S and Pignon JP: Meta-analysis of concomitant versus sequential radiochemotherapy in locally advanced non-small-cell lung cancer. J Clin Oncol 28: 21812190, 2010.

7 De Ruysscher D, Botterweck A, Dirx M, Pijls-Johannesma M, Wanders R, Hochstenbag M, Dingemans AM, Bootsma G, Geraedts W, Simons J, Pitz C and Lambin P: Eligibility for concurrent chemotherapy and radiotherapy of locally advanced lung cancer patients: a prospective, population based study. Ann of oncology 98-102, 2009.

8 Walraven I, Ten Berge M, Damhuis R, Tissing-Tan C, Troost E, Reymen B, Widder J, Koppe F, Van Der Wel A, Vonk E, Coremans I, Bussink J, De Jaeger K, Van Zyp NVDV, El Sharouni S, Knol H, Woutersen $\mathrm{D}$ and Belderbos J: Determinants of sequential versus concurrent chemoradiotherapy in stage III non-small cell lung cancer patients. J Thorac Oncol 10: S539, 2015.
Received June 29, 2016

Revised July 18, 2016

Accepted July 22, 2016 